Trinity University

Digital Commons @ Trinity

Education Faculty Research

Education Department

9-2015

\title{
Applying Response to Intervention to Identify Learning Disabilities in Students With Visual Impairments
}

Beth A. Jones

Heather Haynes Smith

Trinity University, hhaynes@trinity.edu

Lauren Hensley-Maloney

Kristin A. Gansle

Follow this and additional works at: https://digitalcommons.trinity.edu/educ_faculty

Part of the Education Commons

\section{Repository Citation}

Jones, B.A., Smith, H.H., Hensley-Maloney, L., \& Gansle, K.A. (2015). Applying response to intervention to identify learning disabilities in students with visual impairments. Intervention in School and Clinic, 51(1), 28-36. doi: 10.1177/1053451215577475

This Post-Print is brought to you for free and open access by the Education Department at Digital Commons @ Trinity. It has been accepted for inclusion in Education Faculty Research by an authorized administrator of Digital Commons @ Trinity. For more information, please contact jcostanz@trinity.edu. 


\title{
Running Head: APPLYING RTI TO IDENTIFY LD COEXISTING WITH VI
}

Applying Response to Intervention to Identify Learning Disabilities in Students with Visual Impairments

\author{
Beth A. Jones, PhD \\ Texas A\&M University-Commerce \\ Heather Haynes-Smith, $\mathrm{PhD}$ \\ Trinity University \\ Lauren Hensley-Maloney, $\mathrm{PhD}$ \\ Texas A\&M University-Commerce \\ Kristin A. Gansle, $\mathrm{PhD}$ \\ Louisiana State University
}

Correspondence regarding this article should be addressed to Beth A. Jones, $\mathrm{PhD}$, Assistant Professor of Special Education, Texas A\&M University-Commerce, PO Box 3011, Commerce, TX 75429, 903-886-5940, Beth.Jones@ @tamuc.edu 


\begin{abstract}
When visual impairments (VI) and learning disabilities (LD) coexist, it is common for one (typically LD) to go unidentified (Erin \& Koenig, 1997; Layton \& Lock, 2001). Some school districts may be reluctant to identify students as both VI and LD (Layton \& Lock, 2001), potentially causing students to miss out on much needed services (Turnbull \& Turnbull, 2006). Child study teams can find support to address this dual diagnosis using a response to intervention (RTI) framework. This article provides guidance and tools for using a RTI framework in the accurate identification of LD in students with VI.
\end{abstract}

Keywords: visual impairment, learning disability, dual diagnosis, response to intervention 
Applying Response to Intervention to Identify Learning Disabilities in Students with Visual Impairments

Students with visual impairments (VI) are a heterogeneous group comprising about $0.4 \%$ $(239,466)$ of all students $(5,986,644)$ served under the Individuals with Disabilities Education Improvement Act (IDEIA) and $0.04 \%(264,012)$ of the total school age population $(66,002,955)$ (Ferrell, 2000; Office of Special Education and Rehabilitative Services, 2008a; Office of Special Education and Rehabilitative Services, 2008c). Learning disabilities (LD) is the largest disability category served under IDEIA, with $4 \%(2,640,118)$ of all children ages $3-17(66,002,955)$ meeting criteria for LD and $44.6 \%(2,670,043)$ of all students $(5,986,644)$ served under IDEIA (Office of Special Education and Rehabilitative Services, 2008a; Office of Special Education and Rehabilitative Services, 2008b; Office of Special Education and Rehabilitative Services, 2008c). Students with VI often display behaviors similar to those exhibited by students with LD (National Information Center for Children and Youth with Disabilities, 2012; Vaughn, Bos, \& Schumm, 2000). Additionally, LD can, by IDEIA definition, include perceptual disabilities; in diagnosis, general perceptual difficulties can be confused with specific visual perception problems. Furthermore, VI and LD can be comorbid. However, the two conditions are often mistaken for one another, and, in cases where the two coexist, the LD is often unidentified (Erin \& Koenig, 1997; Layton \& Lock, 2001). Early research on comorbid VI and LD suggested $14 \%$ to $45 \%$ of individuals with VI also had LD (Corn \& Ryser, 1989; Erin \& Koenig, 1997; Troughton, 1992; Woods \& Lindsey, 1994). More recently, Wagner and Blackorby (2002) found that $10.2 \%$ of parents of students with LD reported coexisting VI and 3\% of parents of students with VI reported coexisting LD.

\section{The Advantages of Dual Diagnosis}


Given the necessity of simply seeing stimuli in order to accurately interpret and comprehend them, it is not difficult to understand how a student with VI might miss critical early academic skills, complicating and contributing to a LD. Additionally, the confounding effects of possible working memory deficits and the learned helplessness associated with LD on the needs of a student with VI necessitate the need for identification and intervention as soon as the problems become apparent (Jones \& Hensley-Maloney, 2015). For example, due to the time intensive efforts required for students with VI to read course material (whether in Braille or large print) and to reference notes, these students need to be extremely skilled at selecting, organizing and retrieving the most crucial information - a skill that is greatly complicated by the presence of a LD. Further, because students with LD are often viewed as lazy, unorganized, and unmotivated, the additional label can prompt educators to develop teaching techniques that are more responsive to individual needs, usually resulting in improved academic performance (Loftin, 2005). Lastly, students with LD often have issues with self-esteem and adjusting to the school environment. These students can be depressed because, although they are intelligent, they are not learning easily and can be at risk for dropping out of school and/or becoming involved in marginal activities (Loftin, 2005). Identifying LD and appropriate compensatory strategies can be both an emotional and educational benefit (Loftin, 2005). Thus, it is important for educators and child study teams to be aware of the issues associated with these two disorders occurring in tandem and to consider assessment and identification for both of these areas, as failure to accurately identify the presence of both VI and LD may result in students missing out on needed services (Turnbull \& Turnbull, 2006).

\section{Factors Contributing to Underidentification}

Several foundational issues exist which may explain this misidentification or 
underidentification of students with VI who also have LD. The federal definition for LD contains an exclusionary clause stating that LD does not include children who experience difficulty learning solely because of another disability, including a visual disability (IDEIA, 2004). This exclusionary clause may lead some professionals to dismiss the possibility of a dual diagnosis of VI and LD (Layton \& Lock, 2001), as the definition of LD implies that students with LD may not have VI if VI appears to be the only factor contributing to learning problems. However, given the difficulties in determining the cause or even the major contributing factor to LD (Heward, 2013), the reality that it is not yet fully understood how a student's brain is affected by experience and how the experience is affected by the brain (Leonard, 2001), and the fact that a medical diagnosis of LD and its etiology is not available, it seems ill advised to eliminate appropriate interventions for students who appear to have both VI and LD. Rather, targeting the relevant behaviors and developing the most appropriate interventions for both would have the best probability of remediating the difficulties apparent for students with VI and LD (Layton \& Lock, 2001).

In addition to the unintended consequences surrounding the exclusionary clause, academic and behavioral similarities between students with VI or LD further contribute to difficulties with identification. For example, reading difficulties are the most common problem among students with LD (Handler \& Fierson, 2011), and students with VI are often below grade level in reading (Emerson, Holbrook, \& D’Andrea, 2009). Additionally, students with VI and students with LD often lag behind their nondisabled peers in the area of social skill development (Estell et al., 2008; Shapiro, Leiberman, \& Moffett, 2003). Furthermore, VI is often more obvious and recognized earlier than LD; in fact, some districts discourage evaluation for LD before $2^{\text {nd }}$ or $3^{\text {rd }}$ grade, while a student with moderate to severe VI is likely be noticed as having 
a disability in early childhood. VI diagnosis may also be more socially/educationally acceptable than LD, resulting in VI being the more frequently diagnosed impairment of the two when both are present (Erin \& Koenig, 1997; Layton \& Lock, 2001). Given the reality of these diagnostic issues, students may miss opportunities for intervention. Early intervention is critical to the promotion of independence that will likely take longer to achieve than for typically-developing children (Ferrell, 1996).

Clearly, students with coexisting VI and LD need targeted academic interventions, especially related to reading skills. In addition to academic interventions, these students need interventions related to social skill development, the promotion of independence, improving their perceived competence, and building self-determination skills (Jones \& Hensley-Maloney, 2015; Loftin, 2005). Further, it is the associated coping mechanisms students with LD possess that have the greatest influence on outcomes in adult life (Margalit, 2003; Prior, 1996; Raskind, Goldberg, Higgins, \& Herman. 1999). These include a proactive rather than helpless attributional style, perseverance, the ability to access help when needed, self-awareness, and the ability to find creative solutions to overcome challenges (Nunez, et al., 2005; Raskind, et al., 1999; Reiff, Ginsburg, \& Gerber, 1995). Because these coping skills are established at a young age (Prior, Sanson, Smart, \& Oberklaid, 2001; Raskind et al., 1999; Seiffge-Krenke, 2000), as are students’ perceived academic and social competence (Shapiro et al., 2003), early intervention to address these skills is needed for students with VI and LD. Practical considerations for child study teams considering identification of LD and VI within the RTI framework are discussed, followed by considerations for using that framework with students with VI. Additionally, a sample checklist is provided for child study teams to utilize.

\section{Considerations for Applying a Response to Intervention Framework}


The National Center for Response to Intervention, or NCRTI, (2010) gives recommendations regarding the essential components of a Response to Intervention (RTI) framework. This framework includes universal screening, multi-tiered systems of support, progress monitoring, and evidence-based instruction. Although the RTI model was developed originally for the instruction and identification of students solely with LD, it holds promise as a framework to identify students who have coexisting VI and LD. However, to date, the assessment of this comorbidity has remained relatively unexplored (Kamei-Hannan, Holbrook, \& Ricci, 2012). Kamei-Hannan et al. (2012) describe important considerations for using a RTI framework for identifying LD in students with VI.

In order to apply a RTI approach to students with VI, there are important issues for child study teams to address. These considerations, organized by the key components of RTI, are provided as guidance for teams wishing to consider the RTI framework as part of instruction and identification of LD in students with VI. Accurate and meaningful assessment is critical to the development of appropriate and effective interventions. These considerations should be used as discussion and reflection items for child study teams for students with VI in schools implementing RTI. Specific considerations for universal screening; tiered instruction; selection, use and interpretation of assessments for monitoring progress; and evidence-based instruction and intervention are discussed. Figure 1 is a graphical representation of a model for incorporating the recommendations of Kamei-Hannan et al. (2012) into the NCRTI framework.

\section{Universal Screening}

There are many options for screening of a student body for difficulties in a given skill area. In RTI, these can be selected by the team, school, or district and will assist with initial identification of students who may be in need of additional supports. Although standardized 
instruments are acceptable tools when considering instruction and intervention leading to identification of LD with VI, educators need to use caution as standardized tests are usually norm-referenced and may not sufficiently describe abilities of students with VI, as the expectation of multi-disciplinary teams is that most students do not have sensory impairments. Comparing scores of normally sighted students with those who are VI on standardized instruments may be inappropriate (Baker \& Koenig, 1995; Hannan, 2007). Further, when administering informal screening assessments to students with or suspected of having VI, child study teams should consider the conditions under which the student takes the test that may affect the external validity of the assessment (Pressley, 2003). There are also accommodations and modifications to be considered in the assessment of students with VI (Bowen \& Ferrell, 2003). These accommodations and modifications are provided in Table 1.

\section{Multi-tiered Systems of Supports}

To accurately place students with VI on the appropriate tier of RTI, educators must understand that although the student might require direct instruction by a teacher of students with VI, it does not mean the student should automatically be placed on Tier 2 or small group intervention. Rather, the provision of instruction by a qualified teacher of students with VI may be essential to ensuring students with VI are exposed to instruction appropriate to their disability and evidence-based practices that general education teachers may not possess (Kamei-Hannan, et al., 2012). It is essential for teams of educators supporting this system and providing instructional guidance to involve a teacher with special training for students with visual impairments (Kamei-Hannan et al., 2012), thus ensuring data, and its interpretation, are appropriate. In the event that a teacher of students with VI is not available in the district, teams may use the guidelines in this paper to assist them in providing appropriate modifications and 
accommodations. If it becomes apparent that VI and LD are indeed present and the team decides that a VI specialist is appropriate for the student's needs, the district would be required to contract for those services.

\section{Progress Monitoring}

Assessment for instructional purposes is critical to the appropriate education of students with LD and VI. Although they may be useful for identification due to state policy constraints, the treatment validity of standardized measures is likely not as good as curriculum-based measures that are more directly skill-focused (Baker \& Koenig, 1995; Hannan, 2007; Pressley, 2003; Reid, 1998). Alternatively, criterion-referenced measures will also provide more helpful information for planning instruction than standardized measures (Hannan, 2007). The Brigance Comprehensive Inventory of Basic Skills-Revised (CIBS-R) and basic reading inventories are examples of progress monitoring assessments that are commonly used with students with VI. As is the case when providing multi-tiered supports mentioned above, a teacher of students with VI should be consulted when determining appropriate procedures for monitoring progress.

In addition to these measures, several evaluations should be conducted annually for students with VI, including: (a) learning media assessment to determine learning medium (i.e. Braille, print, or both); (b) a functional vision assessment to assess visual efficiency and visual function (see Table 1); and (c) an assistive technology evaluation (Hannan, 2007; Swenson, 2013). These evaluations can be considered part of progress monitoring for students with VI within RTI. Data from these assessments needs to remain current and to be considered as part of the decision when considering changing a student's level of instruction, or tier.

\section{Evidence-based Instruction and Intervention}


Instruction should be provided by highly qualified teachers, including both a general education teacher and a teacher of students with VI. It is imperative that instruction should be direct and evidenced-based (Jones \& Hensley-Maloney, 2015), utilizing instructional practices that have been proven effective through empirical research, a historically challenging aspect of education for individuals with VI (Ferrell, 2006). This component of RTI challenges teachers of students with VI to investigate and implement scientifically validated interventions (KameiHannan et al., 2012).

Ferrell (2006) investigated the bodies of research related to literacy and mathematics instruction for students with VI and provides a summary of the results. Although the author notes that there is a dearth of evidence-based practices available, promising practices include: a) haptic perception is sustained over time, suggesting that concrete hands-on experiences might enhance learning; b) training in and use of low-vision devices increases oral comprehension, reading speed (oral and silent), and the amount of reading accomplished, c) use of concrete mathematics aids can increase computation accuracy; c) comprehension of mathematics concepts can be increased with use of the Talking Calculator; d) The English Language Grammar Method (a method of teaching mathematics by comparing it to English sentence structures) may improve computation, and e) instruction in fingermath (using the fingers for computation) may increase computation accuracy.

Evidence-based instructions also means providing appropriate accommodations to allow the student with VI to access both the general education curriculum and any specialized or “expanded core" curriculum. The expanded core of instruction specific to students with VI might include Braille literacy, visual efficiency, and assistive technology. The results of the learning media assessment should be considered when selecting accommodations and determining 
necessary components of an expanded core curriculum (Jones \& Hnesley-Maloney, 2015).

\section{Recommendations for the Evaluation and Assessment of Students}

With at least a dozen states having adopted a RTI framework as the required approach for LD identification (Zirkel \& Thomas, 2010), some researchers still argue that a comprehensive evaluation, including a standardized ability or IQ assessment, should remain as part of the identification process to address the requirement that students with LD exhibit problems in one or more basic psychological processes (Hale, Kaufman, Naglieri, Kavale, 2006; Ofiesh, 2006). As implementation of RTI often still includes standardized test scores as part of eligibility determination, it is imperative that educators consider how appropriate they are for students with VI and consult with a teacher of students with VI when determining specific procedures for evaluation (Bolt \& Thurlow, 2004; Hannan, 2007; Loftin, 2005; Reid, 1998). These recommendations are provided for those multidisciplinary teams that opt to use standardized assessments.

Examiners conducting standardized assessments of students with VI should use batteries designed for use with this population whenever possible. For academic and achievement testing, the Woodcock-Johnson III Tests of Achievement, with both a large print edition and a Braille Adaptation (WJ III ACH-Braille; Jaffe, Henderson, Evans, McClurg, \& Etter, 2010), is recommended as the only standardized achievement test produced with built-in accommodations for individuals with VI.

Assessment personnel using the WJ III ACH-Braille should meet qualifications for administering the WJ ACH tests (non-Braille forms) in addition to being competent in Braille; if examiners are not competent in Braille they may team with another professional (i.e., a teacher of students with VI) who is competent in Braille to ensure student needs are met during the 
examination. Such a partner is often referred to as an ancillary examiner and may also assist with any specialized equipment with which the primary examiner is not familiar. This ensures the student understands and follows directions, floor and ceiling levels for Braille responses are monitored, and Braille responses are transcribed for the primary examiner. The auxiliary examiner also helps ascertain patterns or errors in responses that may be related to the student's VI or use of special equipment rather than a true academic deficit (Jaffe, 2010).

The Slosson Intelligence Test for Children and Adults (SIT-R3; Larsen \& Slosson, 2000) is recommended for cognitive ability/intelligence testing. The SIT-R3 is a brief, individually administered test of verbal intelligence for use with examinees ages 4-65 years and is the only cognitive/ability assessment tool specifically indicated as appropriate for elementary through high-school aged individuals with VI. The SIT-R3 includes a supplemental manual for use with blind or visually impaired examinees as well as supplemental stimuli sheets with raised and heavy bolded items.

If the SIT-R3 is unavailable, examiners may rely upon verbal subtests drawn from more popular cognitive batteries such as the Wechsler Intelligence Scale for Children, Fourth Edition (Wechsler, 2003) for an estimation of cognitive ability level. Subtests measuring non-verbal abilities which utilize visual stimuli (such as those measuring visual spatial reasoning) may be administered to further understand student limitations, but should never be used as indicators of intellectual ability or in the calculation of a full scale IQ score (Goodman, Evans, \& Loftin, 2011). For additional reference, Loftin (2005) provides a breakdown of the perceived appropriateness of individual subtests within the WISC, WJ-III and other assessment batteries.

\section{VI-LD-RTI Checklist}

In order to guide child study teams in identification of VI and LD, we adapted a 
preliminary model introduced by Kamei-Hannan (2012) to create the VI-LD-RTI Checklist (see

Figure 2) for child study teams to use for the accurate identification of LD in students with VI. This checklist provides a starting point to integrate assessment and intervention for these students. A detailed example of a mock implementation is included on the checklist.

Teams should begin with the "Preliminary Questions" section. These are questions that should be asked upon the first indication of the need for the use of a RTI model with a student with VI, before the multidisciplinary team membership is solidified and effective implementation of RTI tiers begins. This preliminary section addresses the appropriateness of the team members, whether learning media make sense given the child's disabilities, and extant evaluation results.

Once these questions have been addressed and appropriate personnel have been included in team membership, RTI implementation can begin.

Each subsequent section of the VI-LD-RTI Checklist corresponds to one of the three tiers of RTI. As the team and the student go through each step of the process, the team should consider the following issues. First, is instruction being provided by highly qualified personnel: both general educators and teachers of students with VI? If instruction is not being provided by people who are trained to do so, it is impossible for the team to tell whether any resulting lack of response to intervention is a function of inadequate or inappropriate instruction, or of the disability. Second, is the teacher of students with VI providing appropriate data and interpretation of data (curriculum-based assessments vs. standardized measures)? If, for example, the measures employed are not sufficiently sensitive to determine progress over shortterm instructional intervals, they would be inappropriate to this purpose. Third, are data-based decisions used to determine educational programming? This is particularly critical to appropriate use of a RTI process. If programming is not based on data collected, it seems an exercise in 
futility to go through the process of intervention when the team would have no data to support its success or failure and suggest additional avenues of intervention.

The checklist also contains areas for assessment at each tier of RTI. At Tier 1, a simple assessment of whether evidence-based instruction is being provided is completed. This can include an observation of the instructional environment and materials being used with the student. A VI teacher or other specialist may be enlisted to provide that information. At Tier 2, teams should address whether areas in which they have not observed any or unacceptable response to intervention have been addressed with more intensive intervention. If less intensive intervention is appropriate, that change can be made as well. And, in Tier 3, teams should look at the extent to which instruction has been individualized to meet the needs of the student. It is important to remember that before the student is moved to more intensive tiers, the team must reevaluate the learning needs assessment of the student for appropriateness. If a full revaluation is indicated, perhaps to provide more current information in the light of changes, this should be completed before moving forward with more intensive steps of intervention.

Essentially, this checklist is a procedural RTI worksheet. It has items specific to LD and VI to assure that those issues are addressed by teams when needed to respond to the unique needs of students with VI, but allows for a broad approach to intervention that addresses competencies not only of the student, but of the intervention agents.

\section{Intervention for Students with Comorbid Learning Disabilities and Visual Impairments}

Providing effective interventions for students with VI and LD requires unique considerations that are worthy of differentiation from those that would be applicable to students with LD only. As mentioned previously, this population will typically present with difficulties in reading, social skills, perceived competence, independence, and self-determination. In addition 
to the supports traditionally offered to students with LD having difficulty with reading fluency (i.e. flash cards for learning sight words) and/or reading comprehension (i.e. graphic organizers, highlighting, making notes while reading), teachers of students with coexisting VI and LD should work carefully with a reading specialist and VI coaches to understand any adaptive technology equipment and other strategies that may help these students become more successful readers.

Students with VI often miss valuable opportunities for the incidental learning that their sighted peers are exposed to almost constantly (Hatlen \& Curry, 1987). Due to the confounding issues related to working memory deficits and a lack of spontaneous learning stemming from a lack of visual stimuli, these students may need to be taught prerequisite skills. For example, vocabulary instruction may be needed before reading fluency and comprehension interventions can be successful. Effective memory strategies, such as the use of self-talk and tactile clues, should be explicitly taught and overlearning along with frequent review and repetition should be implemented as part of targeted intervention. In general, instructors should keep oral directions short and simple and have the student paraphrase directions back to ensure comprehension (Mather \& Jaffe, 2002).

In sum, and possibly most importantly, instructors should expect that students with VI and LD may need a longer period of support than students with LD only. Thus, child study teams need to consider the duration of employed interventions. It is likely that students with coexisting VI and LD will need extended time, not only for completing tasks, but for processing and responding to intervention. As a result, these students may need to spend a longer period of time within each tier of RTI.

\section{Conclusion}


VI and LD often coexist; however, it is not unusual for one to escape identification (Erin \& Koenig, 1997; Layton \& Lock, 2001). Although the exclusionary clause in the federal definition of LD is intended to prohibit students from being misidentified as LD, it may actually discourage school districts from pursuing a dual diagnosis when, in actuality, both disorders exist and students would benefit from addressing all symptoms (Layton \& Lock, 2001). Additional factors, such as VI perhaps being more socially acceptable, VI presenting earlier and being more obvious, and shared characteristics between the two disabilities, contribute to the failure to identify and address coexisting VI and LD (Erin \& Koenig, 1997; Layton \& Lock, 2001).

Perceiving the learning difficulties of students with comorbid VI and LD as only stemming from the visual system may minimize more global deficits in the learning processes (Layton \& Lock, 2001). In addition, failure to accurately identify the presence of both VI and LD may result in students missing out on needed services (Turnbull \& Turnbull, 2006). Specifically, students with coexisting VI and LD will need academic interventions targeted at reading, as well as instruction related to social skills, independence, perceived competence, and selfdetermination skills (Jones \& Hensley-Maloney, 2015; Loftin, 2005). Furthermore, the confounding effects of deficits associated with LD in a student with an already existing VI make it imperative that he/she is identified and receives early intervention (Jones \& Hensley-Maloney, 2015). Lastly, coping mechanisms of students with LD influence outcomes in adult life (Margalit, 2003; Prior, 1996; Raskind et al.. 1999), and coping patterns are established at a young age (Prior et al., 2001; Raskind et al., 1999; Seiffge-Krenke, 2000). However, students must first be identified in order to receive appropriate interventions. Thus, this article suggests considerations for conceptualizing a RTI framework and provides a practical tool for use by child study teams charged with correctly identifying LD in students with VI. 


\section{References}

Baker, C. P., \& Koenig, A. J. (1995). Relationship of the Blind Learning Aptitude Test to Braille reading skills. Journal of Visual Impairment \& Blindness, 89(5), 440.

Bolt, S. E., \& Thurlow, M. L. (2004). A synthesis of research on five of the most frequently allowed testing accommodations in state policy. Remedial and Special Education, 25 (3), $141-152$.

Bowen, S. K., \& Ferrell, K. A. (2003). Assessment in low-incidence disabilities: The day-to-day realities. Rural Special Education Quarterly, 22(4), 10-19.

Corn, A., \& Ryser, G. (1989). Access to print for students with low vision. Journal of Visual Impairment and Blindness, 86, 68-71.

Emerson, R. W., Holbrook, M. C., \& D’Andrea, F.M. (2009). Acquisition of literacy skills by young children who are blind: Results from the ABC Braille Study. Journal of Visual Impairment \& Blindness, 103, 610-624.

Erin, J. N., \& Koenig, A. J. (1997). The student with visual disability and a learning disability. Journal of Learning Disabilities, 30(3), 309-320.

Estell, D. B., Jones, M. H., Pear, R., Acker, R. V., Farmer, T. W., \& Rodkin, P. C. (2008). Trajectories of social functioning among students with and without learning disabilities. Journal of Learning Disabilities, 41, 5-14.

Ferrell, K. A. (1996). Your child's development. In M. C. Holbrook (Ed.), Children with visual impairments: A parent's guide (pp. 73-96). Bethesda, MD: Woodbine House.

Ferrell, K. A. (2000). Growth and development of young children with visual impairments. In M. C. Holbrook \& A. J. Koenig (Eds.), Foundations of education: Volume 1. History and theory of teaching children and youths with visual impairments ( $2^{\text {nd }}$ ed., pp.111-134). 
New York: AFB Press.

Ferrell, K. (2006). Evidence-based practices for students with visual disabilities. Communication Disorders Quarterly, 28, 42-48.

Goodman, S. A., Evans, C., \& Loftin, M. (2011). Position paper: Intelligence testing of individuals who are blind or visually impaired. Louisville, KY: American Printing House for the Blind. Retrieved from http://www.aph.org/tests/intelligencetesting.html\#resources

Hale, J. B., Kaufman, A., Naglieri, J. A., \& Kavale, K. A. (2006). Implementation of IDEA: Integrating Response to Intervention and Cognitive Assessment Methods. Psychology In The Schools, 43(7), 753-770.

Handler, S. M., \& Fierson, W. M. (2011). Learning disabilities, dyslexia, and vision. Pediatrics, 127, e818-e856.

Hannan, C. K. (2007). Exploring assessment processes in specialized schools for students who are visually impaired. Journal of Visual Impairment \& Blindness, 101, 69-79.

Hatlen, P. H., \& Curry, S. A. (1987). In support of specialized programs for blind and visually impaired children: The impact of vision loss on learning. Journal of Visual Impairment and Blindness, 81(1), 7-13.

Heward, W. L. (2013). Exceptional children: An introduction to special education (10th ed.). Upper Saddle River, NJ: Pearson Education, Inc.

Individuals with Disabilities Education Improvement Act. (2004). [34 CFR 300.307] [20 U.S.C. 1221e-3; 1401(30); 1414(b)(6)] Retrieved from http://idea.ed.gov/explore/view/p/\%2Croot\%2Cdynamic\%2CTopicalBrief\%2C23\%2C

Jaffe, L. (November, 2010). Issues in translating tests into Braille: WJ III Tests of Achievement- 
Braille Adaptation. Unpublished paper presented at the National Association of School Psychologists Annual Conference, Grapevine, TX. Presentation retrieved from http://www.nasponline.org/conventions/handouts2010/unstated/WJ\%20III\%20ACH\%20 Braille-NASP-handouts.pdf

Jaffe, L. E., Henderson, B. W., Evans, C. A., McClurg, L., \& Etter, N. (2010). WoodcockJohnson III Tests of Achievement Normative Update-Braille Adaptation (2nd ed.). Louisville, KY: American Printing House for the Blind.

Jones, B. A. \& Hensley-Maloney, L. (2015, in press). Meeting the needs of students with coexisting visual impairments and learning disabilities. Intervention in School and Clinic. (50)4, 1-8, doi: 10.1177/1053451214546401

Kamei-Hannan, C., Holbrook, M. C., \& Ricci. L. A. (2012). Applying a response-to-intervention model to literacy instruction for students who are blind or have low vision. Journal of Visual Impairment \& Blindness, 106, 69-80.

Larson, S., \& Slosson, S. W. (Eds.). (2000). Slosson Intelligence Test- Revised supplementary manual for use with the blind or visually impaired. East Aurora, NY: Slosson Educational Publications.

Layton, C. \& Lock, R. (2001). Determining learning disabilities in students with low vision. Journal of Visual Impairments \& Blindness, 5, 288-299.

Leonard, C. M. (2001). Imaging brain structure in children: Differentiating language disability and reading disability. Learning Disability Quarterly, 24, 158-176. doi:10.2307/1511241

Loftin, M. (2005). Making Evaluation Meaningful. Austin, TX: Texas School for the Blind and Visually Impaired.

Margalit, M. (2003). Resilience model among individuals with learning disabilities: Proximal 
and distal influences. Learning Disabilities: Research \& Practice, 18(2), 82-86.

Mather, N., \& Jaffe, L.E. (2002). Woodcock-Johnson III: Reports, Recommendations, and Strategies. New York, New York: John Wiley \& Sons Inc.

National Center on Response to Intervention (2010). What is RTI? Retrieved from http://www.rti4success.org

National Information Center for Children and Youth With Disabilities (NICHCY) (2012). Visual impairment, including blindness, Disability Fact Sheet \#13. Author.

Núñez, C. J., Gonzalez-Pienda, J. A., Gonzalez-Pumariega, S., Roces, C., Alvarez, L., \& Gonzalez, P. (2005). Subgroups of attributional profiles in students with learning difficulties and their relation to self-concept and academic goals. Learning Disabilities: Research \& Practice, 20(2), 86-97.

Office of Special Education and Rehabilitative Services (2008a). 30th Annual Report to Congress on the implementation of the Individuals with Disabilities Education Act. Number of students ages 6 through 21 served under IDEA, Part B, and percentage of the population served, by year: Fall 1997 through fall 2006 (Table 9). Retrieved from http://www2.ed.gov/about/reports/annual/osep/2008/parts-b-c/30th-idea-arc.pdf Office of Special Education and Rehabilitative Services (2008b). 30th Annual Report to Congress on the implementation of the Individuals with Disabilities Education Act. Percentage of the population ages 6 through 21 served under IDEA, Part B, by year and disability category: Fall 1997 through fall 2006(Table 10). Retrieved from http://www2.ed.gov/about/reports/annual/osep/2008/parts-b-c/30th-idea-arc.pdf Office of Special Education and Rehabilitative Services (2008c). 30th Annual Report to Congress on the implementation of the Individuals with Disabilities Education Act. 
Percentage of students ages 6 through 21 served under IDEA, Part B, by disability category (Figure 11). Retrieved from http://www2.ed.gov/about/reports/annual/osep/2008/parts-b-c/30th-idea-arc.pdf

Ofiesh, N. (2006). Response to intervention and the identification of specific learning disabilities: Why we need comprehensive evaluations as part of the process. Psychology In The Schools, 43(8), 883-888.

Pressley, M. (2003). A few things reading educators should know about instructional experiments. Reading Teacher, 57(1). Retrieved from http://www.readingonline.org/articles/RT/9-03_Column

Prior, M. (1996). Understanding specific learning difficulties. Philadelphia:Psychology Press.

Prior, M., Sanson, A., Smart, D., \& Oberklaid, F. (2001). Pathways from infancy to adolescence: Australian Temperament Project 1983-2000. Melbourne: Australian Institute of Family Studies.

Raskind, M. H., Goldberg, R. J., Higgins, E. L., \& Herman, K. L. (1999). Patterns of change and predictors of success in individuals with learning disabilities: Results from a twenty year study. Learning Disabilities: Research \& Practice, 14(1), 35-49.

Reid, J. (1998). Assessing the literacy of adults who are visually impaired: Conceptual and measurement issues. Journal of Visual Impairment \& Blindness, 92, 447-452.

Reiff, H. B., Ginsberg, R., \& Gerber, P. J. (1995). New perspectives on teaching from successful adults with learning disabilities. Remedial and Special Education, 16(1), 29-37.

Seiffge-Krenke, I. (2000). Causal links between stressful events, coping style, and adolescent symptomatology. Journal of Adolescence, 23, 657-691.

Shapiro, D. R., Lieberman, L. J., \& Moffett, A. (2003). Strategies to improve perceived 
competence in children with visual impairments. Re:View, 35(2), 69-80.

Simonson, B., MacSuga-Gage, A. S., Briere, D. E., Freeman, J., Myers, D., Scott, T., \& Sugai, G. (2013). Multi-tiered support framework for teachers' classroom management practices: Overview and case study of building the triangle for teachers. Journal of Positive Behavior Interventions, Published online before print April 9, 2013, doi: $10.1177 / 1098300713484062$.

Swenson, A. M. (2013). A second look at large print materials. Retrieved from Connecticut State Department of Education, Special Education Resources Center, Braille Literacy Handouts: http://ctserc.org/s/index.php?option=com_content\&view=article\&id=1193 Troughton, M. (1992). Learning disabilities and how they affect a person's ability to learn contracted braille. Retrieved from http://snow.idrc.ocad.ca/node/155

Turnbull, H. R., \& Turnbull, A. P. (2006). Free appropriate public education $\left(7^{\text {th }}\right.$ ed.), Denver, CO: Love Publishing.

Vaughn, S., Bos, C. S., \& Schumm, J. S. (2000). Teaching exceptional, diverse, and at-risk students in the general education classroom. (2 ${ }^{\text {nd }}$ ed.). Boston: Allyn \& Bacon.

Wagner, M. \& Blackorby, J. (2002). Disability profiles of elementary and middle school students with disabilities. (SRI Project P10656).Office of Special Education Programs, U.S. Department of Education. Retrieved from www.seels.net/info_reports/disability_profiles.htm

Wechsler, D. (2003). Wechsler Intelligence Scale for Children (4th ed.) (WISC-IV). San Antonio, TX: The Psychological Corporation.

Woods, R. \& Lindsey, J. (1994). Perceived and actual mathematical competencies of children with visual impairments and learning disabilities. Psychological Reports, 74, 238. 
Zirkel, P. A., \& Thmoas, L. B. (2010). State laws for RTI: An updated snapshot. Teaching Exceptional Children, 42(3), 56-63. 
- Use standardized instruments with caution, most are normed on sighted individuals 


\begin{tabular}{|c|c|c|c|}
\hline & & & $\begin{array}{l}\text { Considerations Made and Dates of } \\
\text { Intervention }\end{array}$ \\
\hline \multicolumn{3}{|c|}{$\begin{array}{l}\text { Preliminary Questions: } \\
\text { Is the teacher of students with visual impairments an active member of } \\
\text { the child study team? } \\
\text { Was a learning media assessment conducted to determine the student's } \\
\text { learning medium (large print, Braille, or a combination)? } \\
\text { Was the student's visual efficiency and visual function evaluated? } \\
\text { Was an assistive technology evaluation conducted? }\end{array}$} & \multirow{2}{*}{$\begin{array}{l}\text { Mrs. Riley, teacher of VI, is a } \\
\text { member of Team; } \\
\text { Learning Media Assessment } \\
\text { conducted-8/30/13; } \\
\text { Functional Vision \& AT } \\
\text { Evacuation conducted-9/3/13; } \\
\text { large print with optical aids are } \\
\text { best for Alex. AT evaluator met } \\
\text { with teachers on } 9 / 5 / 13 \text {. }\end{array}$} \\
\hline \multirow{3}{*}{$\begin{array}{l}\text { Is instruction } \\
\text { being provided } \\
\text { by highly } \\
\text { qualified } \\
\text { personnel (both } \\
\text { general } \\
\text { educators and } \\
\text { teachers of } \\
\text { students with } \\
\text { VI)? }\end{array}$} & $\begin{array}{l}\text { Level of } \\
\text { RTI }\end{array}$ & $\begin{array}{l}\text { Items to be Addressed by Child } \\
\text { Study Team }\end{array}$ & \\
\hline & Tier 1 & $\begin{array}{l}\text { Is the student being exposed to } \\
\text { direct, evidence-based instruction in } \\
\text { the core and expanded core } \\
\text { curriculum? }\end{array}$ & $\begin{array}{l}\text { Alex is served in general } \\
\text { education, with Mrs. Pope, and } \\
\text { receives itinerant services from a } \\
\text { VI specialist, Mrs. Riley. He is not } \\
\text { performing well on curriculum- } \\
\text { based measures of reading or } \\
\text { writing. }\end{array}$ \\
\hline & \multicolumn{2}{|c|}{$\begin{array}{l}\text { Before a tier is changed, ensure data from a } \\
\text { learning media assessment is current and } \\
\text { available. }\end{array}$} & $\begin{array}{l}\text { 10/2/13- Child Study Team } \\
\text { reviewed assessment for planning } \\
\text { instruction. }\end{array}$ \\
\hline \multirow{4}{*}{$\begin{array}{l}\text { Is the teacher of } \\
\text { students with VI } \\
\text { providing } \\
\text { appropriate data } \\
\text { and } \\
\text { interpretation of } \\
\text { data (curriculum- } \\
\text { based } \\
\text { assessments vs. } \\
\text { standardized } \\
\text { measures)? } \\
\text { Are data-based } \\
\text { decisions used to } \\
\text { determine } \\
\text { educational } \\
\text { programming? }\end{array}$} & Tier 2 & $\begin{array}{l}\text { Is instruction designed to address } \\
\text { areas of nonresponse? } \\
\text { Is additional instruction being } \\
\text { provided by a low vision specialist, } \\
\text { occupational therapist (OT), or } \\
\text { reading specialist? }\end{array}$ & $\begin{array}{l}\text { Alex is struggling with reading } \\
\text { fluency and comprehension, as } \\
\text { well as writing. He will receive } \\
\text { specialized instruction from the } \\
\text { reading specialist and OT } 1 \mathrm{x} / \mathrm{wk} \\
\text { for } 6 \text { weeks. Brigance data was } \\
\text { reviewed by Mrs. Riley. }\end{array}$ \\
\hline & \multicolumn{2}{|c|}{$\begin{array}{l}\text { Before a tier is changed, ensure data from a } \\
\text { learning media assessment is current and } \\
\text { available. }\end{array}$} & $\begin{array}{l}\text { 12/4/13- The Learning Media } \\
\text { Assessment is reviewed to ensure } \\
\text { that large print with selected } \\
\text { devices is the best medium. }\end{array}$ \\
\hline & Tier 3 & $\begin{array}{l}\text { Is instruction highly individualized } \\
\text { and designed to meet the needs of the } \\
\text { student? } \\
\text { Is intensity adjusted by increasing the } \\
\text { duration or frequency of instruction? } \\
\text { Is instruction supported by other } \\
\text { specialists (special education, OT, } \\
\text { PT, or low vision? }\end{array}$ & $\begin{array}{l}\text { Services from the reading } \\
\text { specialist will be increased to } 3 \mathrm{x} \text { a } \\
\text { week for } 45 \text { minute for } 6 \text { weeks. } \\
\text { Mrs. Riley consults with the } \\
\text { reading specialist \& OT to ensure } \\
\text { AT is facilitating instruction. }\end{array}$ \\
\hline & $\begin{array}{l}\text { Special } \\
\text { Education } \\
\text { Referral/ } \\
\text { Evaluation }\end{array}$ & $\begin{array}{l}\text { What considerations will be made } \\
\text { regarding threats to external, internal, } \\
\text { and construct validity for } \\
\text { assessments to be used? }\end{array}$ & $\begin{array}{l}\text { Referral made 1/16/14 Examiner } \\
\text { will utilize an auxiliary examiner } \\
\text { and rely only on verbal subtests of } \\
\text { IQ measures; Braille } \\
\text { inappropriate. }\end{array}$ \\
\hline
\end{tabular}




\section{Figure Captions}

Figure 1. Four Key Components in a RTI Framework and Considerations for LD Identification in Students with VI

Figure 2. A Sample Completed VI-LD-RTI Checklist 
Table 1

Factors to Consider for Accommodations and Modifications when Assessing Students with or Suspected of VI

Accommodations $\quad$ Modifications

1. materials (large print or Braille versions, 1. type and severity of the student's vision use of optical devices, reducing loss

background clutter)

2. time/scheduling (frequent breaks, extended time)

3. response (use of a tape recorder, scribe, or answer sheets in Braille)

4. administration (provision of work stands or yellow acetate sheets)

5. setting/environment (describing the room layout, checking for glare, and creating contrast)

6. general (call the student by name and, if appropriate, use touch, read with an expressive voice, and read the functional vision report in advance to learn how the individual student uses vision)
2. student's familiarity with the modifications

3. effect of the modifications on the test's validity

4. ability to maintain the purpose of the assessment 